\title{
The Digital Divide in Healthcare: A Socio-Cultural Perspective of Digital Health Literacy
}

\author{
Humira Ehrari \\ Department of Management \\ School of Business \& Social Sciences \\ Aarhus University \\ Homiraaa@hotmail.com
}

\author{
Lise Tordrup \\ Department of Management \\ School of Business \& Social Sciences \\ Aarhus University \\ lith@mgmt.au.dk
}

\author{
Sune Dueholm Müller \\ Department of Management \\ School of Business \& Social Sciences \\ Aarhus University \\ sdm@mgmt.au.dk
}

\begin{abstract}
As the use of IT for health management increases, threats to exacerbate existing health inequalities increases. Through semi-structured expert interviews, this qualitative study aims to examine the SocioCultural characteristics associated with access to and use of technologies for health managing purposes and its relationship with health literacy. Inspired by Bourdieu, the paper uses a socio-cultural perspective to understand the choices and lifestyle of individuals, based on the underlying human mechanisms that may function as determinants of the (in)equality which digitalization of health services may entail. The study focuses on the following question: How do social factors create and reproduce (in)equality in behavioral skills, regarding digital health technologies? The study contributes with a multidimensional perspective on social factors that influences the use and acceptance of digital health technologies from the expert's perspectives.
\end{abstract}

\section{Introduction}

Healthcare is gradually moving from face-to-face patient-centered care to technology-supported virtual care [1]. The potential of digital health technologies ${ }^{1}$ in supporting health management is apparent [2]-[5]. Digital health technologies can for example support independent living by assisting in monitoring and managing health [6], making different treatments available, and supporting connections between homes and the outside world [7]. Existing services in the form of physical consultations are increasingly being replaced by virtual care (e.g., online consultations, selfservice apps, and real-time monitoring of vital signs) [8]. Digital health technologies can contribute to the improvement of quality of life and care of patients (e.g. people with chronic disease using digital health technologies), as it supports collaboration between care providers, involvement of relatives, and compliance with medical guidelines and treatment plans [7].

However, digital health technologies can also be a barrier to healthcare access, as not all patients have the skills to use and exploit digital health technologies effectively. The increased use of digital health technologies requires skills, such as digital health literacy, which can be defined as: 'the ability to seek, find, understand, appraise, and apply information from digital sources to manage and cope with health issues" [9].

As healthcare continues to apply digital technologies for health management, the digital divide in health increases; the gap continues to grow between those who have access, ability, and motivation to use digital solutions, and those who do not [10]. Within healthcare, the digital divide has forced a stark disparity in digital health technology usage and adoption [11]. Thus, digital health literacy, in the digital health context becomes an important capital, which affords individuals the ability and motivation to use health technologies to manage health.

This makes digital health literacy an important area for information system research, as digital health literacy can be used as a tool to determine the individual's intention towards the adoption and acceptance of digital health technologies for health managing purposes (Elaboration in section 2).

Limited digital health literacy has been associated with limited access to relevant health information and thus limited abilities to manage one's health and utilize preventive services, resulting in e.g., poor chronic disease management

\footnotetext{
1 The term Digital health technology is used as an umbrella term for digital solutions supporting healthcare (e.g., eHealth, mHealth, telehealth, and telemedicine, screen visits, apps).
} 
outcomes and higher medical costs [12]-[14]. Therefore a socio-cultural perspective on digital literacy is necessary to understand digital lives [14], [25], [29].

The sociologist Pierre Bourdieu points - through the theory of practice [18] - to the importance of behavioral skills concerning social inequality [19]. The theory allows us to gain a socio-cultural perspective to understand the choices and lifestyle of individuals, based on the underlying human mechanisms [18], which can function as determinants of the (in)equality which digitalization of health services may entail [20]. This involves an understanding of how different forms of capital (e.g., power, knowledge, culture, and social capital) can play a crucial role in building habitus (skills using digital health technologies) within the field of health management. Theory of practice can help us understand and predict the underlying challenges related to why some people are better to use and adopt digital technologies, than others. Each concept can help characterize the rationales behind patients' attitudes toward using digital health technologies and this will help to ensure equity.

Theory of practice is frequently applied in different contexts; however, few studies have applied the theory of practice in the context of digital health, and no studies have yet applied the theory to explain the creation of digital literacy for technology usage behavior for health management purposes.

Thus, through a qualitative case study research design with semi-structured telephone expert interviews, we investigate the effect of digital health literacy as an ability that affects patients' choices; thereby providing a greater understanding of patients' autonomy and competency. E.g., how the social factors (capital, habitus, and field) form behavioral skills for the use of digital health technologies. Through Bourdieu as the analytical perspective driving on content analysis of six semi-structured interviews, the study gets into the importance of the conditions and opportunities an individual must have to obtain the desired living conditions and take on the assigned responsibilities for this. Drawing on the key concepts of Theory of Practice by Bourdieu, we ask the following question:

How do social factors create and reproduce (in)equality in behavioral skills to use digital health technologies?

To answer the research questions, the study revolves around diabetes patients with foot ulcers as a case, and provides illustrative examples of patient engagement in health management, using telemedicine and the foot ulcers app.

\section{Related work: digital health literacy}

The technological developments in the health sector and the increased research in the field have expanded the definitions of health literacy [15], [21], [22]. From a definition concerning the individual's ability to understand the basic information on how to live a healthy lifestyle [23], to the ability and skills to obtain, process, and understand complex health information, and to make informed decisions that improve one's health-related quality of life [16], [23]-[27].

Health literacy is an individual's ability to live a healthy lifestyle and use health-related resources efficiently [28]. Digital health literacy is an extension of health literacy cf. figure 1 , where the definition of health literacy is used in the context of technology [9]. It is defined as the individual's cognitive and social skills that determine individuals' motivation, opportunity, and ability to use digital health technologies to access and understand the information in digital platforms, and use it in ways that promote and maintain health and improve health-related quality of life [16], [20], [29], [30].

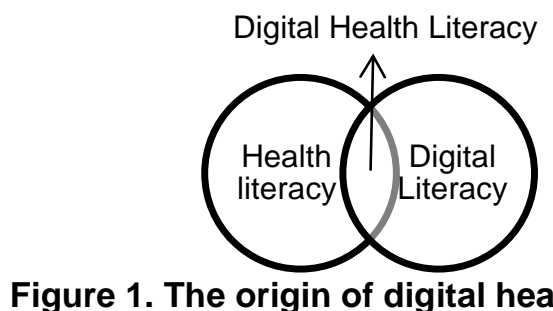

Figure 1. The origin of digital health literacy [9]

In the field of information systems, there is a growing body of research describing factors related to the acceptance of technological solutions for health management purposes. E.g., the Technology Acceptance Model [31], the Theory of Reasoned Action [31], Unified Theory of Acceptance and Use of Technologies [32], and the Theory of Planned Behavior [33]. These have placed great emphasis on explaining the mechanisms (usefulness, ease of use, social factors and facilitating conditions, performing, and effort expectancy) of a given system, which affects the intention of the users to use a given technology in an everyday context [34]. The area of technology acceptance has primarily focused on initial adoption, under the implicit assumption that technology usage is mainly determined by the intention that is influenced by productivity-oriented factors (e.g., efficiency in the workplace) [35].

Technology-related beliefs have been explored in connection with an individual's behavior in technological contexts. These include individual's readiness to adopt new technologies, and their extent of 
technology use [31]-[34]. However, in the context of digital health technology usage, these models are not assuming digital health literacy as a tool to determine the individual's intention towards the adoption and acceptance of digital health technologies for health managing purposes.

[15] is one of the first to use the term 'digital literacy' and define it as: "The ability to understand and use information in multiple formats from a wide variety of sources when it is presented via computers" [15]. [16] conveys a very functional view of digital literacy, it develops a conceptual framework of digital literacy, and it defines it as a collection of five skills, which are necessary for communication in digital environments [16]. E.g., the skills needed for online communication and collaboration (socio-emotional skills), the ability to "read" and produce symbols in addition to text (Photo visual skills), the ability to use and create new combinations of existing information (Reproductive competence). The ability to search and navigate in information environments (Branch competence). Finally, the skills needed to evaluate online content critically (Information skills).

[17] presents a conceptual framework that considers digital literacy as the intersection of the individual's technical, cognitive, and socio-emotional competencies [17]. The technical dimension includes the individual's skills in being able to use information systems. The cognitive dimension refers to the individual's ability to understand how to use and produce digital sources. Finally, the socio-emotional dimension refers to an individual's skills in responsible technology use [17].

Furthermore, [36] define digital literacy as the result of seven factors, including demographic and psychological factors, social influences, and the ability to use technologies [36]. Digital literacy is an automated process that largely happens simply through individuals' exposure to and use of various digital health technologies [36]. Fundamental to all these aspects of digital literacy is either critical literacy or the acknowledgement that information on the digital platforms is created by someone for a specific purpose and must be assessed as such. To use a digital tool sensibly (protecting oneself from abuse), the users must have the strength and ability (digital literacy) to act responsibly [37].

This recognition raises a need for a sophisticated understanding of the impact of social and environmental conditions on digital health literacy.

\section{Theoretical framework}

The basis of Bourdieu's theory of practice is that the behavior skills of individuals (habitus) are influenced by their environment (field), available resources (capital)
[19]. The three factors each constitute sub-elements in a coherent conceptual universe, which together provide the individual behavioral skills, figure 2 .

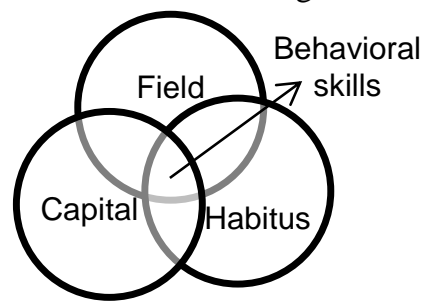

\section{Figure 2. Behavior skills according to Bourdieu [19]}

Field is the individual's social space, which gives the individual opportunities for development and unfoldment. Capital is the individual's acquired resources, that enable the individual to be part of the social space and influence habitus (behavioral skills) [18], [41]. Habitus links/connects social structure with the actions of the individual [18].

Furthermore, Bourdieu explains that the individual's behavior is based on proactive forces; "Symbolic power", which is an "invisible disciplinary force" that influences the thoughts which the individual has about oneself and one's surroundings [19]. Symbolic power can help explain why individuals do not question the rules and logic that prevail within the field (digital environments) in which individuals act (habitus) [18], [41].

\section{Method}

A qualitative case study research design with semistructured telephone expert interviews was utilized. The qualitative research design was used, as it allows for obtaining insights into the participants' observations, experiences, and opinions, with patients using digital tools for health management purposes. This provides valuable knowledge of understanding the importance of digital health literacy, and the effective use of digital health technologies for health management purposes.

\subsection{Foot ulcer as case study}

Diabetes foot ulcers are wounds or open sores that will not heal and keep returning. The treatment of foot ulcers is complex and requires close interdisciplinary collaboration between patients and health professionals.

This makes the Ulcers-App (Sår-App) an interesting case when studying the importance of digital health literacy in the context of managing the complex disease, which requires interdisciplinary collaboration. The SårApp aims to potentially strengthen the patients' control 
of their course of treatment, help to oversee the wound healing process, and at the same time allow the citizen to share relevant information with their health professionals.

The experts in this paper shared their experiences with patients using telemedicine and the Sår-App. However, the Sår-App is in its initial implementing phase, the experts were not able to tell much of their experiences with it. Therefore, they added their experiences with telemedicine too.

\subsection{Participants}

Variation concerning participants within qualitative research is important to gain nuanced insights into a research question [38]. The snowball recruiting strategy was used to recruit participants (experts in Denmark) who represented both novices and experts within the field of digital health technology. The participants were asked to participate in a phone interview to provide perspectives and insights into the importance of digital health literacy and the patients' ability (habitus, field, capital) to manage health via digital health technologies. We interviewed six experts (Table 1) with different roles who have been near the same patient groups. Since the Foot Ulcer App is in its very early stages, the experts were only involved until enough depth and richness related to the usage of the Foot Ulcer App and telemedicine for managing foot ulcers was explored.

\begin{tabular}{|l|l|l|}
\hline \multicolumn{3}{|c|}{$\begin{array}{l}\text { Table 1. An overview of participants' } \\
\text { background and their contributions }\end{array}$} \\
\hline \# & Background & Contribution \\
\hline P1 & $\begin{array}{l}\text { Ph.D. Currently } \\
\text { working as a } \\
\text { researcher at Danish } \\
\text { Technological } \\
\text { Institute }\end{array}$ & $\begin{array}{l}\text { Knowledge about Sår- } \\
\text { App and experiences } \\
\text { with people managing } \\
\text { diabetic foot ulcers via } \\
\text { App }\end{array}$ \\
\hline P2 & $\begin{array}{l}\text { Medical Doctor \& } \\
\text { consultant working } \\
\text { at the Knowledge } \\
\text { Center for Wound } \\
\text { Healing }\end{array}$ & $\begin{array}{l}\text { Shared experience with } \\
\text { telemedicine \& sårApp } \\
\text { from a hospital setting. }\end{array}$ \\
\hline P3 & $\begin{array}{l}\text { Consultant at the } \\
\text { Aarhus municipality }\end{array}$ & $\begin{array}{l}\text { Shared experience with } \\
\text { patients from a homecare } \\
\text { setting. }\end{array}$ \\
\hline P4 & $\begin{array}{l}\text { Podiatrist working } \\
\text { with foot ulcers }\end{array}$ & $\begin{array}{l}\text { Shared experience with } \\
\text { patients' ability to } \\
\text { manage foot ulcers }\end{array}$ \\
\hline P5 & $\begin{array}{l}\text { Home care social \& } \\
\text { health assistant }\end{array}$ & $\begin{array}{l}\text { Shared experience with a } \\
\text { patient discharged from } \\
\text { hospitals \& rehab }\end{array}$ \\
\hline P6 & $\begin{array}{l}\text { An elder person } \\
\text { working voluntarily } \\
\text { for ældresagen (Ngo } \\
\text { for old people) }\end{array}$ & $\begin{array}{l}\text { Shared experience with } \\
\text { technology \& the } \\
\text { importance of digital } \\
\text { health literacy }\end{array}$ \\
\hline
\end{tabular}

\subsection{Data collection}

The interview procedure was inspired by the qualitative interviewing method presented by [39]. A semi-structured approach was chosen to manage the topics of the interviews, while still allowing for flexibility in the process [40]. This makes room for questions that were not included in the interview guide, if new ideas arose through the interview [41]. Hence, the approach was useful to understand the visions, perspectives, stories of the experts related to their observations, and experiences with patients using digital health technologies [42].

The interviews were conducted through one-on-one telephone interviews following a pre-developed interview guide, aimed at capturing the expert's experiences and insights. Each interview lasted 25-30 minutes. When no new insights or expectations were revealed, data saturation occurred, making further interviews unnecessary [38]. All interviews were audiorecorded and transcribed verbatim. Participants were anonymized and named after a confidential system, known by the researchers.

\subsection{Ethics}

Conducting interviews is a moral practice wherein the interviewer must be aware of the asymmetric relationship [43]. Attentiveness and humbleness were strived throughout the interviews to avoid causing any undue stress and to ensure that the participants felt confident with participating [44]. Allowing participants to share their stories and freely express their expectations was facilitated by adopting a welcoming and open attitude [43]. This attitude was achieved by creating a relaxed atmosphere, providing a friendly and approachable tone of speech [45].

\subsection{Data analysis}

To capture user experience and interpret the interview transcripts the content analysis [46] approach was used. To analyze the data, we used a grounded theory approach, where the theory of practice is used on reflection to the analysis and discussion of the results. We coded each transcript independently and discussed the results to obtain inter-reviewer reliability. We then conducted content analysis by identifying individual themes from the data. Inspired by [46], we then placed these themes under perceptions about digital health literacy, and health management adapted the identified themes to the theoretical grounding of Theory of Practice. 


\section{Results}

In the following, we combine Bourdieu's key concepts with the empirical data to explain the importance of digital health literacy and how social factors create and reproduce (in)equality in behavioral skills, in regard to digital health technologies. The theory of practice does not directly tell us anything about digital health literacy and technology acceptance, but their application in connection with the acceptance of health technologies allows us to explain the driving forces which influence the inner and outer motivation behind users' behavior. Using this analytical lens helps us understand and characterize the rationales behind patients' attitudes to using health technologies.

\begin{tabular}{|c|c|c|}
\hline $\begin{array}{l}\text { Theory of } \\
\text { practice } \\
\text { concepts }\end{array}$ & Behavioral skills & $\begin{array}{l}\text { Creation of digital } \\
\text { health literacy }\end{array}$ \\
\hline Field & $\begin{array}{l}\text { - Individual's } \\
\text { social spaces }\end{array}$ & $\begin{array}{l}\text { - Access and } \\
\text { familiarity with the } \\
\text { health technologies }\end{array}$ \\
\hline Capital & $\begin{array}{l}\text { - Individual's } \\
\text { ability to } \\
\text { unfold in } \\
\text { social spaces. } \\
\text { - The relative } \\
\text { value of } \\
\text { capital } \\
\text { depends on the } \\
\text { field in which } \\
\text { it is brought } \\
\text { into play. } \\
\text { Through the } \\
\text { capitals, } \\
\text { individuals can } \\
\text { gain influence } \\
\text { in the field. }\end{array}$ & $\begin{array}{l}\text { - Access to } \\
\text { relationships with } \\
\text { others with } \\
\text { knowledge of health } \\
\text { technology } \\
\text { - Technical expertise, } \\
\text { ability to acquire } \\
\text { technology \& } \\
\text { training. } \\
\text { - Expectations, } \\
\text { ambitions, and } \\
\text { attitudes towards the } \\
\text { use of health } \\
\text { technology. }\end{array}$ \\
\hline Habitus & $\begin{array}{l}\text { - Value \& norm } \\
\text { systems } \\
\text { describe } \\
\text { bodily and } \\
\text { cognitive } \\
\text { structures that } \\
\text { underlie } \\
\text { human actions, } \\
\text { the opinions } \\
\text { they have, and } \\
\text { the choices } \\
\text { they make. }\end{array}$ & $\begin{array}{l}\text { Previous experience } \\
\text { with IT increases the } \\
\text { perception of its } \\
\text { usability, usefulness, } \\
\text { motivation, and } \\
\text { ability to understand } \\
\text { and use digital } \\
\text { health technologies. }\end{array}$ \\
\hline
\end{tabular}

\begin{tabular}{|l|l|l|}
\hline $\begin{array}{l}\text { Symbolic } \\
\text { power }\end{array}$ & $\begin{array}{l}\text { - The thoughts } \\
\text { of an } \\
\text { individual } \\
\text { about } \\
\text { themselves \& } \\
\text { their } \\
\text { surroundings. }\end{array}$ & $\begin{array}{l}\text { Communication and } \\
\text { negotiations on the } \\
\text { use of technologies } \\
\text { - The decision to } \\
\text { restrict or deny } \\
\text { access to } \\
\text { technology. } \\
\text { explains how } \\
\text { individuals do } \\
\text { not question } \\
\text { the rules and } \\
\text { logic that } \\
\text { prevail within } \\
\text { the field in } \\
\text { which they act } \\
\text { and fight for } \\
\text { influence. }\end{array}$ \\
\hline
\end{tabular}

\subsection{Field}

The experts indicated that both patients and health professionals are very positive about the use of technologies for managing their health when asked about their use concerning communication, monitoring, or consultation:

" The fact that you can get much more frequent measurements, there been collaboration problems, a lot that goes lost between hospital visits. So, the fact that you can use the health technologies to remind "minimize the gaps" between consultations is a great thing.... (P1)

The following quotes reflect a unique way of being "in touch with patients" through technology and a new way of sharing details about health status and daily life through the technologies (telemedicine \& ulcer app that both health professionals and patients appreciate). The use of telemedicine minimizes the geographic gap between patients and their health professionals. Using telemedicine services along with the ulcer-app allows patients to e.g., send a picture of the ulcer and show their health professionals what it looks like. In the same way, it allows health professionals to stay in touch with and give ongoing qualified feedback to the patients.

"Health technology is a great thing; patients can send a picture and say "try to see what it looks like. This is how it is now" and there can be a "thumbs up" from caregiver "you call if it starts getting worst" (P1)

The use of telemedicine reduces the burden on both health professionals and patients. P6 indicates that field (familiarity with technologies) is an important factor, that has eased her life. She uses telemedicine and other 
tools to e.g., make an appointment or get in touch with care professionals.

"I make my appointment with my doctor and podiatrist over the internet. That means I do not have to go to her so many times. If I must order a new medicine, then I do it over the internet, I do everything on the internet in that regard. The same with my physiotherapist, I do too- she writes text messages and she writes emails to me. That's because I've been using the internet for many, many years now". (P6)

However, there are also some worries about the use of technologies in everyday life. The concerns are mostly about handling the solutions for everyday life (field) and being able to use the technical expertise effectively (capital and habitus), as the ability to navigate in complex health environments and remotely communicate with care professionals. The experts highlighted the importance of digital health literacy as an important factor when using the devices or other technical solutions according to the health professionals' guidelines and pharmaceutical regimes.

In this regard, P4 \& P5 mentioned the glucosemeasuring device, which is a device attached to the patient's arm. Despite its usefulness and ease of use, some patients have difficulties understanding how to operate with the device, due to technical, cognitive, and socio-emotional competencies. E.g., lack of previous experiences, familiarity, and social support make some patients doubt how close it should be to their bodies, how to synchronize the device so the data is sent to care professionals at the right time. Lack of such skills makes some patients fail using the device, and instead, they go back to measure it by pricking.

Another example, which all experts mentioned, was the relief footwear, which is special footwear targeted diabetes foot ulcers. It is not a digital device, but the experts mentioned it anyway, as it serves as a good example for explaining the importance of having health literacy to complying with health-related guidelines and healthy lifestyles. The patients and the relatives who have some extend of health literacy, can easily understand the importance of using it, versus those who don't have this understanding, and can be hard to convince. Those patients are having higher odds of being hospitalized and for having longer hospital admission periods (P5).

In continuation of the same question, we also asked if there are differences in characteristics related to profiles of patients. All experts indicated that there is no difference related to the socioeconomic status of a patient. However, older patients are more likely to have lower levels of digital health literacy than younger ones.
Many old people are not used to modern technologies; lack of (field) familiarity and access to the technologies differentiate the need and preferences of old and young patients. Due to lack of field and habitus, the old patients do not feel any need to navigate on digital platforms or use digital health technologies. Related to the use of telemedicine, $\mathrm{P} 4$ said:

"Many old people are not used to use technologies, there for the elderly do not have the same need to follow the treatment as the younger ones". (p4)

As seen in the above quotations, patients' digital literacy influences their ability to get involved in digital health management. People with low digital health literacy seem to have low interest in using telemedicine.

\subsection{Habitus}

We asked the experts about the extent to which the participants (at the time of the interview) used telemedicine and the ulcer app, and the reasons for not using it, as well as who helps them solve their technical problems. The experts indicated that the participants' habitus or attitude toward the use of digital health technologies are mostly influenced by their habitus and capital. Previous experience with digital technologies increases the perception of its usability and usefulness and motivates to understand and use digital health technologies effectively.

"I've been using the internet for many years. There are a lot of people who cannot...]. I have a friend; she gets everything by post. She cannot do it over the Internet... The biggest problem is getting the technical help you need, especially as you get older..." (P6)

Through our empirical data, we can see a connection between field and habitus. The experts indicated that the participants who have previously had experience with technologies can easily use technologies for health management too. However, the experts also indicated, that they are having different types of patients. Some people do not even know what a computer or a cellphone is. On the other hand, there are those patients who have smart technologies, such as robot vacuum cleaners, at their homes, or patients who are navigating in digital platforms to follow their treatment regimes.

In this regard, P3 said that most of their patients do not use e-boks, which is a necessity for most citizens. 
"There are patients who are not very often particularly technologically minded. Many of them do not even have an e-boks ${ }^{2}(\mathrm{P} 3)$

The result shows that citizens who have learned to use technologies earlier in their lives find it easy to accept new solutions daily (create a new field and habitus). Most of them explain the lack of experience with technologies with a lack of interest, and as too time-consuming (lack of habitus and capital).

\subsection{Capital}

Patients who do not have experience with technologies have a hard time getting used to telemedicine and the Foot Ulcer App. They are therefore dependent on help from others (social capital).

"I have a good friend in Sweden who helps with the internet and computer over "TeamViewer", where he logs on.... the same with my phone...I have been lucky with a good friend, but there are people who have no one...". (P6)

Older people who do not have a network of relatives (social capital) are less willing to use technological solutions, than citizens who have a circle of people from whom they can seek advice and support. Such older people without help from others cannot excess the digital health technologies or platforms. The most vulnerable citizens tend to get stressed using it. They perceive it as an aggravation of their situation, rather than a help. Therefore, many older digital users rely on the help of relatives.

These patients' field (living conditions, limited social space), lack of capital (technical skills, social network backing them), habitus (thoughts and attitudes about their autonomy and freedom), and symbolic power (progressive resistance) make them protect their autonomy and privacy. However, they get cut off from basic opportunities from which they could benefit, e.g., e-boks. To elaborate, using P6 as an example, P6's field provides her with a network of objective relationships, which carries various forms of capital that help her to deal with technologies in everyday life. This reflects how a person's access to social capital is a powerful tool for constructing a person's habitus. P6 is a case of positive social influence, where she through her capital (friend) achieves new forms of symbolic capital (technical expertise), which enables her to navigate in

\footnotetext{
${ }^{2}$ E-box an electronic mailing system, associated with civil registration number. Used by public entities to communicate with citizens.
}

digital information environments and use digital health technologies appropriately (form new habitus).

However, the patients who lack capital are likely to carry the heaviest burden in terms of diseasemanagement conditions. The above is an example of how systematic differences in living conditions and social factors between people create and reproduce (in)equality in behavioral skills when using digital health technologies.

".. But of course, there is inequality in society; Do you have a relative who can help you? Is it the world's best wound nurse you get visits from, who bothers to help you with a little extra in relation to some digital support, etc." (P1)

In addition, older people's motivation to learn to use technologies often comes directly and indirectly from family and friends (social capital), who encourage them to get started. Here we see a strong connection between Bourdieu's concepts (field, capital, and habitus), where the presence of specific experiences and conditions influences the individual in a positive direction.

To get into the importance of digital health literacy and the importance of capital and habitus, we asked to what extent the patients involve their relatives in decisions of whether to use a given health technology or not. The experts indicated that they always involve relatives. Because, when offering patients new initiatives, it somehow influences the relatives, spouse, or children who are living with the patients. Sometimes the relatives are good at understanding and supporting the patient on their choices. As an example, if patients are doubtful about using a certain tool, they consult with their families. In most cases, it has been a successor. E.g., the relatives comfort the patients not to worry about using certain health technology.

"Many older people want to have their relatives with them when there are to be some new initiatives because sometimes it is also some major things in the home that, for example, need to be changed, so the relatives are often involved." (P4)

"I have a good friend in Sweden, whenever I doubt something, I asked him. and then he guides me if it is safe to use or not. In the same way, many of my old friends consults with their children" (P6)

However, involving relatives can in some cases also have a negative effect. One of the experts shared a scenario where the patient's spouse prevents him from 
using telemedicine because the spouse felt that using it stressed her sick husband. They find it a worsening of their situation, rather than help. The spouse here used her symbolic power to protect her sick husband.

\subsection{Symbolic power}

To get an insight into the importance of digital health literacy and symbolic power, we asked the experts if they ever experienced patients rejecting any kind of treatment, and how they managed the situations.

The experts indicated that they try to acknowledge the patient's opinion, but at the same time offering empowerment (knowledge about the risks of rejecting certain treatment or tools).

"The provider tries to convince through training and assistance, which they can learn to use the tool and thus be part of the digital community" (P4).

If you follow symbolic thinking, there are two types of power involved. The power of patients to determine their social positions and health conditions. The power of health professionals to persuade and discipline. The care provider in this case acts as an exerciser of power even if at the same time showing an understanding and respect for the patient. It is simply a different kind of power than the one based on coercion and control.

"You cannot just demand that people do it. In fact, I think both health professionals and the citizens they need to get dressed for. There is a lot around the training and getting ready for it." (P3)

The results demonstrate that it is not the practical factors that are the cause of the digital inequality, it is, on the contrary, the behavioral skills within everyone (access, knowledge, previous experience).

An important element in the understanding of the digital inequality in health, and the development thereof, are the behavioral competencies that individuals acquire throughout life [30] cf. Figure 3; i.e., shows interesting connections between capital and conditions, such as health and well-being, behavioral norms, and social spaces [47], [48].

When it comes to telemedicine \& Sår-App, it is, according to the expert, voluntary to use. If a patient wants to use it, they can do so, otherwise, their choices are respected. However, the health professionals try to convince the patient to use it, using the symbolic power to make them aware of the potentials and limitations of their choices.

As P3, P4, and P6 indicated, knowledge (capital), familiarity (field), and previous experiences (habitus) give a stronger perception of the applicability of the technology and thus motivate patients to get actively engaged in their health, by using the online platform, communicating with a caregiver, and suggest treatment option or question current treatments regimes.

Symbolic power

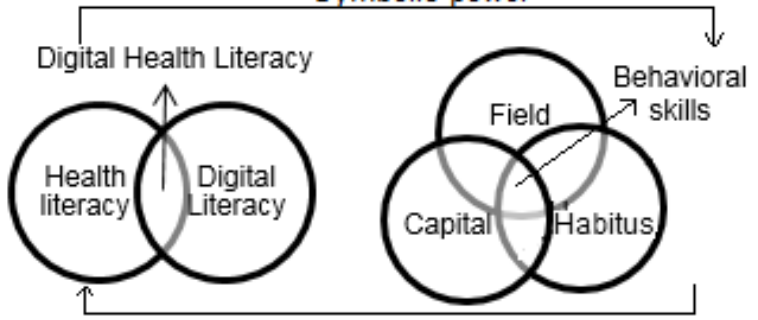

Figure 3. behavioral skills and the creation of digital health literacy

Through our study, it becomes clear that digital health literacy as a factor of behavioral skills is of great importance in how digital technologies can be used among the elderly. This makes digital health literacy a capital that is influenced by individuals' social space (field and habitus). The more experience an individual has within the digital tool, the more literacy they gain, and the more their habitus to use such tool are influenced.

\section{Discussion and conclusion}

This qualitative case study aimed to investigate how social factors create and reproduce (in)equality in behavioral skills in regard to digital health technologies.

The finding indicates that the underlying human intentions, as well as one's own understanding and experiences, influence one's choice to use digital tools. The choice is not just about having the right information, but also the right support, confidence, and the ability to use tools effectively (capital and habitus). In healthcare, lack of such capital leads to disparities in health technology adoption.

Regarding the Socio-Cultural characteristics of people who use the technologies to manage their health, the study showed that underlying human intentions (motivation, ability, and opportunity), as well as one's own understanding and experiences (cultural capital) have an impact on one's choices. Familiarity (field) and previous experiences (habitus) provide a strong perception of the applicability of the technology and thus motivated foot ulcers patients to use the Sår-App and telemedicine.

In addition, individual's motivation to learn how to use technologies often comes directly and indirectly from their social network, which encourages them to get started. We here see a strong connection between Bourdieu's concepts (field, capital, and habitus), where the presence of specific experiences and conditions 
influences the individual in a positive direction. In this regard, digital health literacy is an important skill, which gives the patient capital and symbolic power to manage their health (field) and improve their quality of life (habitus).

An important element in the understanding of the digital inequality in health, and the development thereof, are the behavioral skills that individuals acquire throughout life. For example, there are interesting connections between capital and conditions, such as health and well-being, behavioral norms, and social spaces. In this regard, digital health literacy provides power and is included as an element in the opportunity space for digitization of healthcare services. The more literacy we have available in the field of health, the more factors which could have an impact on our health, including the importance of technological solutions in relation to health promotion and prevention, can be recognized.

This slightly alternative understanding of behavioral skills raises some interesting questions when we try to understand the autonomy and possibilities of action of the individual; how human resources empower and how they are included as an element in given discourses. A strong trend in the study shows that access to various forms of capital can play a crucial role in building habitus in the field of digital health technologies.

Experience and motivation are thus perhaps more significant factors in relation to using technologies than age and education are. However, this study is too small to draw this conclusion. We would therefore argue larger studies examining this context more closely. If we want to avoid the social inequality that the digitalization of healthcare can entail, it requires that the new digital initiatives reflect these groups' options for behavioral and empowerment in the future strategy for the digitalization of healthcare services.

In addition, it is important that people themselves take responsibility, are aware of their health, and have the desire and will to change their living conditions. This understanding leads to health professionals having to acknowledge the patient's strengths and weaknesses, and thus strengthen them according to their needs [49].

\section{Acknowledgment}

We thank all the experts who participated in the study and those who helped us to recruit the experts.

\section{References}

[1] S. Rauv, "The impact of technology in healthcare: Trends and examples," elcom, 2017.

[2] M. M. Baig, H. Gholamhosseini, and M. J. Connolly, "A comprehensive survey of wearable and wireless ECG monitoring systems for older adults," Med. Biol. Eng. Comput., 2013, doi: 10.1007/s11517-012-1021-6.

[3] P. Leijdekkers and V. Gay, "A self-test to detect a heart attack using a mobile phone and wearable sensors," 2008, doi: 10.1109/CBMS.2008.59.

[4] A. Auricchio et al., "Real-life time and distance covered by lay first responders alerted by means of smartphone-application: Implications for early initiation of cardiopulmonary resuscitation and access to automatic external defibrillators,"

Resuscitation, 2019, doi: 10.1016/j.resuscitation.2019.05.023.

[5] C. M. Smith, "Lay first-responders alerted to out-ofhospital cardiac arrest by smartphone app - Not so novel any longer, and it's time to do more,"

Resuscitation. 2019, doi:

10.1016/j.resuscitation.2019.06.007.

[6] D. Lupton, "Quantifying the body: Monitoring and measuring health in the age of mHealth technologies," Crit. Public Health, 2013, doi: 10.1080/09581596.2013.794931.

[7] J. van Hoof, G. Demiris, and E. J. M. Wouters, Handbook of smart homes, health care and wellbeing. 2016.

[8] D. Regioner, "Regionernes samarbejde om digitalisering SUNDHED FOR DIG," 2020.

[9] P. Dunn and E. Hazzard, "Technology approaches to digital health literacy," Artic. Int. J. Cardiol., 2019, doi: 10.1016/j.ijcard.2019.06.039.

[10] J. J. P. A. Hsieh, A. Rai, and M. Keil, “Addressing digital inequality for the socioeconomically disadvantaged through government initiatives: Forms of capital that affect ICT utilization," Inf. Syst. Res., 2011, doi: 10.1287/isre.1090.0256.

[11] N. P. Gordon and M. C. Hornbrook, "Older adults' readiness to engage with eHealth patient education and self-care resources: A cross-sectional survey," BMC Health Serv. Res., 2018, doi: 10.1186/s12913018-2986-0.

[12] L. Gimeno-Feliu, A. Calderón-Larrañaga, ... E. D.F., and U. 2017, "Multimorbidity and immigrant status: associations with area of origin and length of residence in host country," academic.oup.com.

[13] S. Jatrana, S. Siva, R. Pasupuleti, and K.

Richardson, "Nativity, duration of residence and chronic health conditions in Australia: Do trends converge towards the native-born population?," Elsevier, 2014, doi: 10.1016/j.socscimed.2014.08.008.

[14] J. Huh, A. E. Jo, A. Prause, and A. C. D. Dooley, "The Impact of Nativity on Chronic Diseases, SelfRated Health and Comorbidity Status of Asian and Hispanic Immigrants," Artic. J. Immigr. Minor. Heal., 2008, doi: 10.1007/s10903-007-9065-7.

[15] P. Gilster and P. Glister, "Digital Literacy Piercing Purple Want more papers like this?," 1997.

[16] Y. Eshet-alkalai, "Digital Literacy: A Conceptual Framework for Survival Skills in the Digital Era," Pool, 2004.

[17] W. Ng, "Can we teach digital natives digital 
literacy?," Comput. Educ., vol. 59, no. 3, pp. 10651078, Nov. 2012, doi:

10.1016/j.compedu.2012.04.016.

[18] P. Bourdieu, "Outline of a Theory of Practice," in The New Social Theory Reader, 2020.

[19] A. P. Lyons, P. Bourdieu, and R. Nice, "Outline of a Theory of Practice," ASA Rev. Books, vol. 6, p. 232, 1980, doi: $10.2307 / 532672$.

[20] K. Sørensen et al., "Health literacy and public health: A systematic review and integration of definitions and models," BMC Public Health, vol. 12, no. 1. 2012, doi: 10.1186/1471-2458-12-80.

[21] L. Muslic, D. J. Buric, M. Markelic, and S. M. Milanovic, "Mental health literacy," Soc. Psihijatr., vol. 48, no. 3, 2021, doi: 10.24869/SPSIH.2020.324.

[22] C. Liu et al., "What is the meaning of health literacy? A systematic review and qualitative synthesis," Family Medicine and Community Health, vol. 8, no. 2. 2020, doi: 10.1136/fmch-2020000351.

[23] N. D. Berkman, T. C. Davis, and L. Mccormack, "Journal of Health Communication Health Literacy: What Is It?," Springer, vol. 15, no. SUPPL. 2, pp. 919, 2010, doi: 10.1080/10810730.2010.499985.

[24] D. Nutbeam, "The evolving concept of health literacy," Soc. Sci. Med., vol. 67, no. 12, pp. 20722078, Dec. 2008, doi:

10.1016/j.socscimed.2008.09.050.

[25] S. C. Ratzan, "Health literacy: Communication for the public good," Health Promotion International, vol. 16, no. 2. Oxford Academic, pp. 207-214, Jun. 01, 2001, doi: 10.1093/heapro/16.2.207.

[26] G. Demiris, "New era for the consumer health informatics research agenda," Heal. Syst., 2012, doi: 10.1057/hs.2012.7.

[27] B. J. Smith, K. C. Tang, and D. Nutbeam, "WHO Health Promotion Glossary: new terms," Health Promot. Int., vol. 21, no. 4, 2006, doi: 10.1093/heapro/dal033.

[28] K. Sørensen, "Health Literacy," in International Encyclopedia of the Social \& Behavioral Sciences: Second Edition, Elsevier Inc., 2015, pp. 653-656.

[29] B. B. Visscher et al., "Evidence on the effectiveness of health literacy interventions in the EU: A systematic review," BMC Public Health, vol. 18, no. 1, 2018, doi: 10.1186/s12889-018-6331-7.

[30] S. Van den Broucke, "Health literacy: a critical concept for public health," Arch. Public Heal., vol. 72, no. 1, Dec. 2014, doi: 10.1186/2049-3258-7210.

[31] F. D. Davis, "A technology acceptance model for empirically testing new end-user information systems: Theory and results," Management, vol. Ph.D., p. 291, 1985, doi: oclc/56932490.

[32] V. Venkatesh, M. G. Morris, G. B. Davis, and F. D. Davis, "User acceptance of information technology: Toward a unified view," MIS Q. Manag. Inf. Syst., 2003, doi: 10.2307/30036540.

[33] G. Godin and G. Kok, "The theory of planned behavior: A review of its applications to health- related behaviors," Am. J. Heal. Promot., 1996, doi: 10.4278/0890-1171-11.2.87.

[34] K. Sohn and O. Kwon, "Technology acceptance theories and factors influencing artificial Intelligence-based intelligent products," Telemat. Informatics, 2020, doi: 10.1016/j.tele.2019.101324.

[35] M. Limayem, S. G. Hirt, and C. M. K. Cheung, "How habit limits the predictive power of intention: The case of information systems continuance," MIS Q. Manag. Inf. Syst., 2007, doi: 10.2307/25148817.

[36] Q. Wang, M. D. Myers, and D. Sundaram, "Digital natives and digital immigrants: Towards a model of digital fluency," Bus. Inf. Syst. Eng., vol. 5, no. 6, pp. 409-419, Nov. 2013, doi: 10.1007/s12599-0130296-y.

[37] S. Webber and B. Johnston, "Information literacy: Conceptions, context and the formation of a discipline," J. Inf. Lit., vol. 11, no. 1, pp. 156-183, 2017, doi: 10.11645/11.1.2205.

[38] D. . Polit and C. . Beck, Essentials of Nursing Research: Appraising Evidence for Nursing Practice. 2018.

[39] K. Moen and A. L. Middelthon, "Qualitative Research Methods," in Research in Medical and Biological Sciences: From Planning and Preparation to Grant Application and Publication, 2015.

[40] V. C. Virginia Braun, Successful Qualitative Research: A Practical Guide for Beginners. SAGE publication Ltd, 2013.

[41] G. M. Ginn and S. L. Munn, "Interviews: Learning the Craft of Qualitative Research Interviewing, Third Edition, by Svend Brinkmann and Steinar Kvale. Thousand Oaks, CA: Sage, 2015. 405 pages, $\$ 60.00$ (paperback).," New Horizons Adult Educ. Hum. Resour. Dev., 2019, doi: 10.1002/nha3.20251.

[42] C. GarcÍa-Peña, L. M. Gutiérrez-Robledo, and M. U. Pérez-Zepeda, Aging research - methodological issues. 2015.

[43] S. Kvale and S. Brinkmann, InterView: Det kvalitative forskningsinterview som håndvark. 2015.

[44] S. Angel, "Grasping the experience of the other from an interview: self-transposition in use.," Int. J. Qual. Stud. Health Well-being, vol. 8, p. 20634, Jan. 2013, doi: 10.3402/qhw.v8i0.20634.

[45] J. Fog, "On the Basis of the Conversation: The Qualitative Reseach Interviewe.," Akad. Forlag, Kobenhavn, 2004.

[46] M. Miles, A. Huberman, and J. Saldaña, Qualitative Data Analysis: A Methods Sourcebook, Third Edit. SAGE Publications Ltd (CA), 2014.

[47] L. Otto, "Sundhed i praksis," in Folkesundhed - $i$ et kritisk perspektiv, 2009.

[48] H. T. Pernille Tanggaard Andersen, Sundheds sociologi En grundbog. Hans Reitzels forlag, 2012.

[49] C. Jensen and G. T. Svendsen, "Giving money to strangers: European welfare states and social trust," Int. J. Soc. Welf., 2011, doi: 10.1111/j.14682397.2009.00668.x. 